\title{
Assessment of Desertification Dynamics in Machakos County, Kenya
}

\author{
Mark Kipkurwa Boitt ${ }^{*}$, Patrick Ambi Odima \\ Department of Geomatics Engineering and GIS, Jomo Kenyatta University of Agriculture and Technology, Kenya
}

Copyright $\bigcirc 2017$ by authors, all rights reserved. Authors agree that this article remains permanently open access under the terms of the Creative Commons Attribution License 4.0 International License

\begin{abstract}
Many countries face desertification as a challenge, and Kenya is not an exception to this. Desertification means an intensification of desert like conditions and a decline in biological productivity. The Princeton University Dictionary defines it as "the process of fertile land transforming into desert typically as a result of deforestation, drought or improper/inappropriate agriculture". Desert areas are usually sparsely populated, because it is very difficult to carry out most productive human activities such as farming, and also due to the harsh weather conditions. Often, desertification leads to the migration of human and animal populations to more productive areas. This causes overpopulation in the more productive areas, giving rise to more problems. Remote Sensing techniques have proven to be effective, and have been used worldwide for environmental studies. The availability of free data from satellites such as Landsat has provided a cheap and efficient method of conducting such studies. Thus it is necessary to use current, efficient and cheap methods such as Remote Sensing technology in order to assess desertification trends in the country. Many parameters have been used globally to assess desertification, and those used in this study include NDVI (Normalized Difference Vegetation Index, TGSI (Topsoil Grain Size Index) and Albedo. The aim of this research was to assess desertification dynamics in Machakos County, Kenya. The period of this assessment was between 1990 and 2010. It is realized that desertification can be mapped using the methods of NDVI, TGSI and Albedo. Environmental, human and social activities are factors that determine the desertification of a given area or region.
\end{abstract}

Keywords Desertification, Remote Sensing, NDVI, TGSI, Albedo

\section{Introduction}

Desertification has been defined by the United Nations
Convention to Combat Desertification (UNCCD) as "land degradation in arid, semiarid and dry sub-humid areas through natural processes as well as human activities". Human activities such as agriculture, overgrazing and deforestation are been considered as parameters that causes desertification with both physical and socio-economic impacts [1]. Desertification is a complex phenomenon that is dependent on many aspects. A desertification monitoring system for sub-Saharan Africa was developed and it uses mainly the continental-scale remotely sensed data [2].

Several approaches have been developed to use to map desertification. Researchers have used vegetation cover, wind speeds, erosion levels [3], time-series analysis [4], Surface emissivity from satellite derived data [5], soil salinization limits [6] among many other approaches which are in themselves posing a challenge. Mapping from entirely remote sensing techniques coupled with NDVI, Top Soil Grain Index (TGSI) and surface albedo is what we experiment in this paper.

Machakos County lies in one of the dry regions of Kenya. It neighbors Nairobi, the capital of the country, and as such, it impacts heavily on Kenya's capital. The government of Kenya has warned that an increasing number of Kenyan population is being threatened by desertification. One of the sustainable development goals is to sustainably manage forests, combat desertification, reduce and reverse land degradation, and halt biodiversity loss [7].

Machakos County faces a big threat from desertification due to various reasons. It is Kenya's largest exporter of sand to the other counties; sand harvesting in the county has resulted in drying up of some of the rivers. This has resulted in reduction of substantial amount of water in the county. Most of the locals use firewood and charcoal as the main source of fuel. This is a major cause of desertification in Machakos County. Furthermore, farming on slopes has resulted in destruction of forests and water catchment areas, leading to desertification.

The aim of this research was to assess desertification in Machakos County using Remote Sensing through (a) mapping NDVI, TGSI and Albedo in Machakos County, (b) 
determination of the areas with the highest desertification in the County and (c) developing desertification maps as aids in the achievement of sustainable development goals.

\subsection{Study Area}

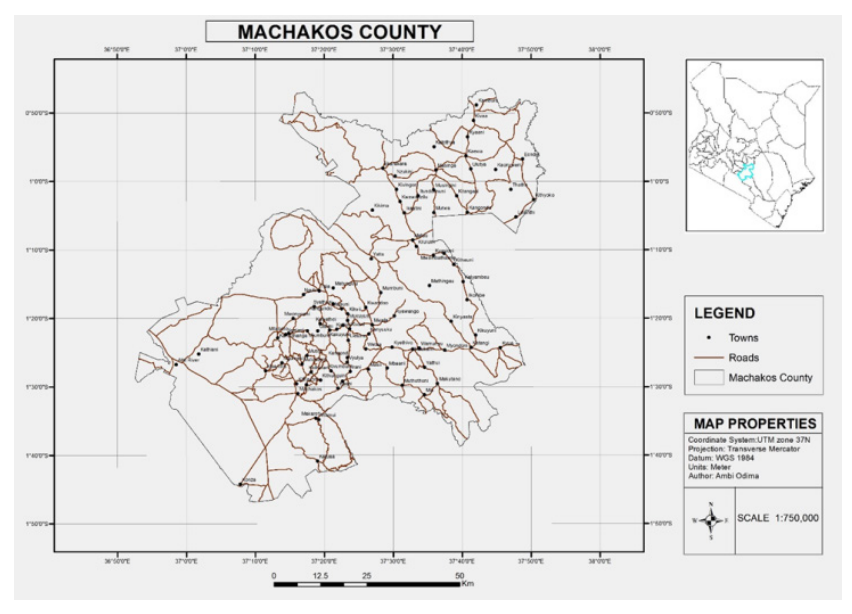

Figure 1. Study Area, Machakos County

The area covered by this study is Machakos County. Machakos County is one of the forty-seven counties in Kenya. To the North the county borders Embu, Murang'a and Kiambu counties; to the west Nairobi and Kajiado counties; to the south Makueni county; and to the East, Kitui county. The county has an area of $6208.2 \mathrm{Km}^{2}$, most of which is semi-arid. The county is divided into eight sub counties namely; Masinga, Yatta, Kangundo, Matungulu, Kathiani, Mavoko, Machakos Town and Mwala. The County has a total of 40 wards and 75 Locations. It lies between latitudes $0^{\circ} 45^{\prime}$ South and $1^{\circ} 31^{\prime}$ South and longitudes $36^{\circ} 45^{\prime}$ East and $37^{\circ} 45^{\prime}$ East (Figure 1). The Machakos County region regularly recurs as a classic example of land degradation in accounts dating back to the 1930s, Dregne et al. [8] and state policies have continuously been devised to address this concern. Rural residents report frequent crop failures and water shortages, and food relief has become a permanent feature of rural life. This is why it is the key to monitor and assess desertification in this county.

\section{Materials and Methods}

The study is based on Machakos County, one of the dry regions of Kenya. The research considers the use of multi-temporal Landsat Satellite Imagery, acquired from the USGS (United States Geological Survey) website. The satellite data was acquired for the years 1990, 2000 and 2010. Boundary data for Machakos County was acquired from KODI (Kenya Open Data Initiative) website. Three parameters were derived from the satellite images, namely NDVI (Normalized Difference Vegetation Index), TGSI (Topsoil Grain Size Index) and Albedo. Using Decision Tree Classification, the three parameters were used to come up with desertification maps for Machakos County, for the chosen epochs (Figure 2).

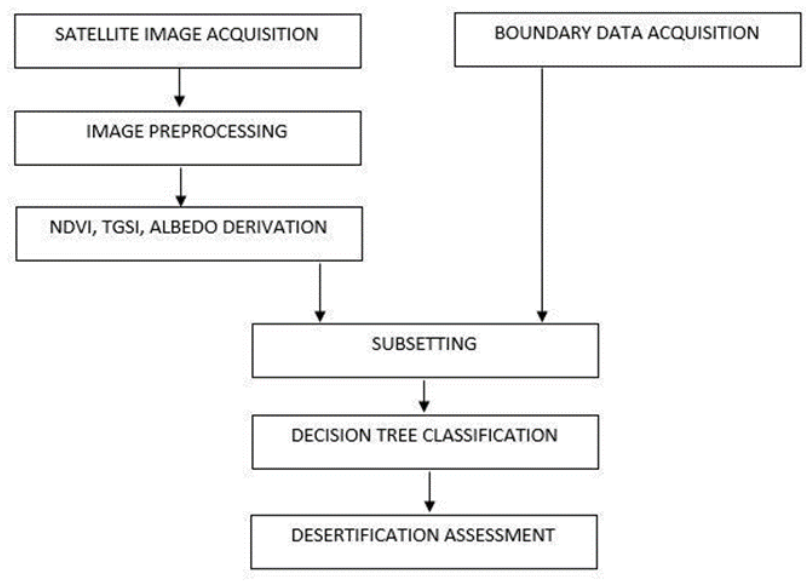

Figure 2. Desertification Flow Chart

\subsection{Albedo}

Surface albedo quantifies the fraction of the sunlight reflected by the surface of the Earth. Some studies e.g. Robinove et al. [9] have shown that increasing land surface albedo implies a degradation of land quality. For derivation of Albedo, original DNs (Digital Numbers) of the satellite images are first converted to TOA (Top of Atmosphere) Reflectance values. This is done using the Two Steps Process. The first step is to convert the DN to radiance values. The second step converts the radiance data to TOA reflectance. Albedo for Landsat Images may then be calculated as:

$$
\begin{aligned}
& \text { Albedo }=(0.356 B+0.130 R+0.373 R+0.085 \text { SWIR } 1+ \\
& 0.072 S W I R 2-0.0018 / 1.016)
\end{aligned}
$$

Where B is the Blue band, R is the Red band, SWIR1 is the Short Wave Infrared 1 band and SWIR2 is the Short Wave Infrared 2 band.

\subsection{Normalized Difference Vegetation Index (NDVI)}

The most common form of vegetation index is the Normalized Difference Vegetation Index (NDVI). The NDVI is the difference between the red and near-infrared band combination, divided by the sum of the red and near-infrared band combination:

$$
N D V I=(N I R-R) /(N I R+R)
$$

Where NIR is the Near Infrared band, and $R$ is the Red band. NDVI values range from +1.0 to -1.0. Areas of barren rock, sand, or snow usually show very low NDVI values. Sparse vegetation such as shrubs and grasslands crops show moderate NDVI values, while high NDVI values (approximately 0.6 to 0.9 ) correspond to dense vegetation at their peak growth stage.

\subsection{Topsoil Grain Size Index (TGSI)}

Topsoil Grain Size Index (TGSI) was developed based on 
the field survey of soil surface spectral reflectance and laboratory analyses of soil grain composition. Even one rainfall can significantly increase the vegetation cover. Thus, NDVI can misinterpret the actual degree of desertification [10]. To overcome this problem, Wang et al. [10] proposed a new index, topsoil grain size index (TGSI), which is associated with the mechanical composition of topsoil. It indicates the coarsening of topsoil grain size as a manifestation of an area undergoing desertification. The more severe the desertification, the coarser the topsoil grain size composition. TGSI may be obtained as:

$$
T G S I=(R-B) /(R+B+G)
$$

where $\mathrm{R}, \mathrm{B}$ and $\mathrm{G}$ are the red, blue and green bands of the remote sensing data respectively.

\subsection{Decision Tree Classification}

The Decision Tree (DT) is a suitable approach for classification. It can employ tree-structured rules recursively to partition the data set feature spaces into increasingly homogenous classes based on a splitting criterion e.g. Xu et al. [11]. DT classification has been used for vegetation mapping and soil mapping in various remote sensing studies. Zheng et al. [12] states that Decision tree classification algorithms have significant potential for Remote sensing data classification. A tree decision classification was formulated for assessment of desertification in Machakos County. The tree decision classification catered for the spatial extent of Machakos County, and the climatic context. Albedo, TGSI and NDVI were reclassified into two classes each, Low (1) and High (2). Desertification was graded into three classes: Low (1), Medium (2) and High (3). Assessment was done as follows:

$$
\begin{gathered}
\text { Low NDVI 1, High Albedo 2, High TGSI } 2= \\
=\text { High Desertification } 3
\end{gathered}
$$

Low NDVI 1, High Albedo 2, Low TGSI 1 = $=$ Medium Desertification 2

Low NDVI 1, Low Albedo 1, High TGSI 2 = $=$ Medium Desertification 2

Else, Low Desertification 1.

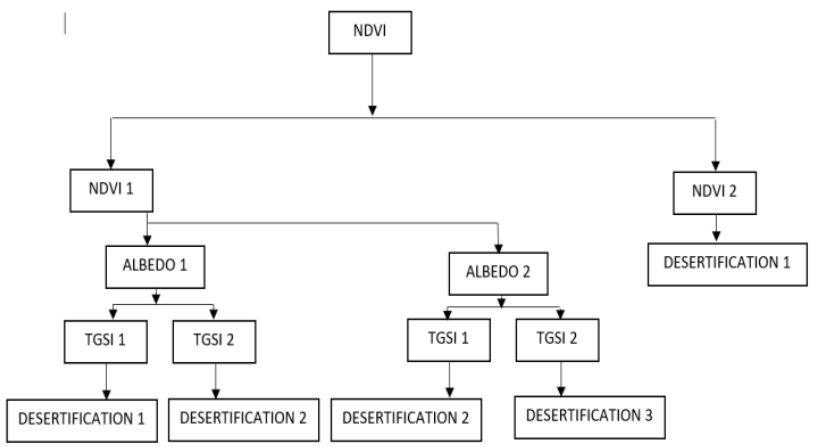

Figure 3. Desertification assessment workflow.

\section{Results and Discussion}

Figure 4 below shows that there was no desert in the county. It only shows some few patches of red color (high desertification) which could be considered negligible as compared to the size of the map area.

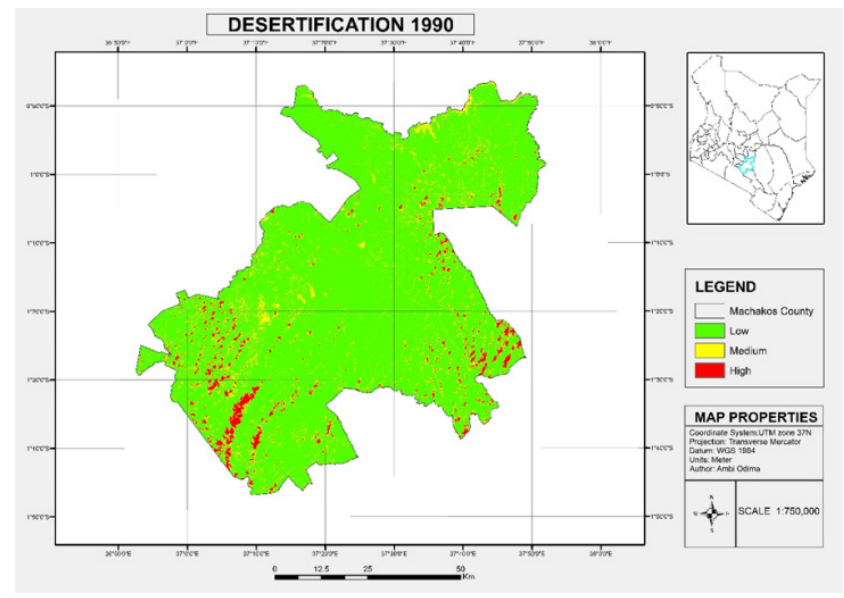

Figure 4. Desertification 1990

Figure 5 below shows desertification which has increased in the last 10 years. Almost all of the image towards the south west and north-east parts are classified as deserts from the approach. This would have been brought about several factors for instance the La Niña effect of 2000 after the El-Niño of 1997 in Kenya for instance Boitt et al. [13]. Figure 6 below shows medium to high desertification in the year 2010. It is evident that there was an improvement as compared to the year 2000. This is attributed to some human activities in the area, environmental concerns such as afforestation and forest conservation measures and even change in policies. With the focus on green development, it is evident that the result is a bit an improvement from 2010 and not close to 1990 when it was green.

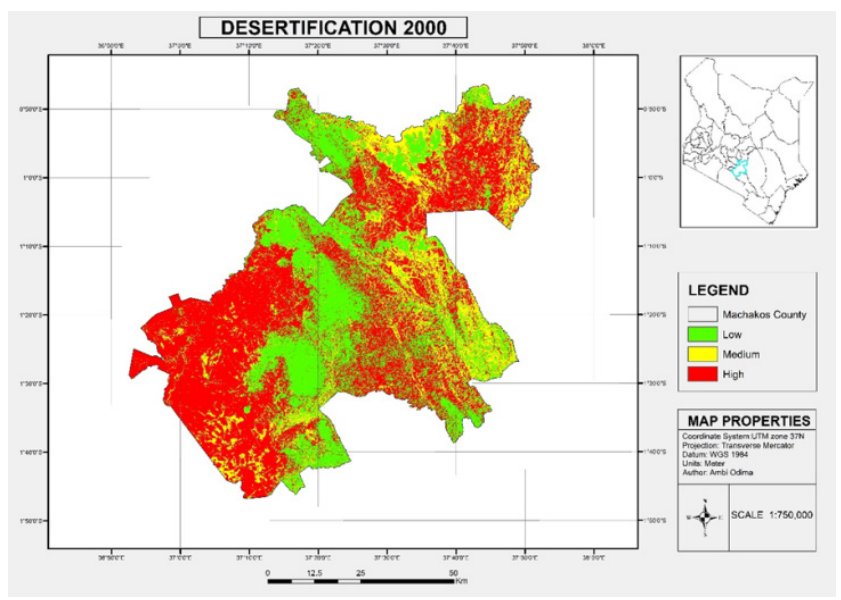

Figure 5. Desertification 2000 


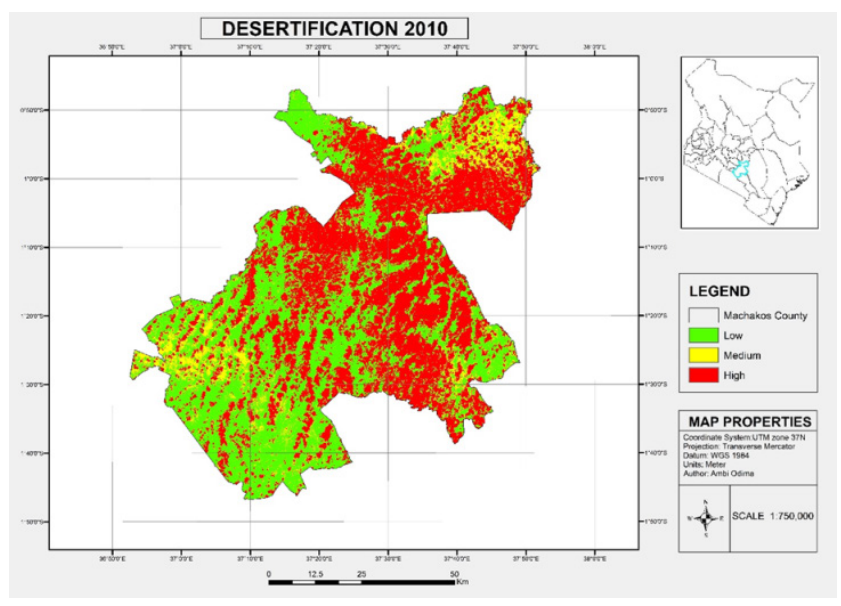

Figure 6. Desertification 2010

Machakos County rarely receives a lot of rainfall throughout the year and it is not on steep lands and it can be argued that human activities and population increase could be one of the main factors that accelerates the desertification in this area and is argued similarly by dynamic causal patterns of desertification by Geist \& Lambin [14].

The use of NDVI, TGSI and Albedo derivation coupled with remote sensing data provides a general view of the desertification in a given area. In this study, we assessed and mapped the desertification dynamics in Machakos County between 1990 and 2010 using Landsat images. Using calibration information with satellite data, all the images were radiometrically and atmospherically corrected using techniques such as Dark Object Subtraction (DOS). Decision Tree (DT) classification techniques using NDVI, TGSI, and land surface albedo were used to derive final classification for the observation periods. A total of 6911896 pixels were tested. The changes between pixels were then evaluated and quantified (Table 1) as percentages.

Table 1. Desertification quantification

\begin{tabular}{|c|c|c|c|}
\hline YEAR / \% COVER & LOW & MEDIUM & HIGH \\
\hline 1990 & 87.77 & 9.13 & 3.10 \\
\hline 2000 & 31.40 & 19.11 & 49.49 \\
\hline 2009 & 57.13 & 24.77 & 18.10 \\
\hline
\end{tabular}

\section{Conclusions}

There is an increase in the areal coverage of medium and high desertification grades from 1990 - 2010. There is a decrease in the areal coverage of low desertification grade in the county, from 1990 - 2010. Desertification has shifted spatially in the county, from $1990-2010$.

The El-Niño of 1997 rains would have been a possible change in the desertification dynamics. Coupled with the effects of after the rains, the image in Figure 5 shows increased desertification which would be possibly attributed to the La Niña effect of 2000. Low rainfall harvesting, high water run-off and increased human activities on land are some of the factors accelerating desertification in a given landscape.

\section{Acknowledgements}

We are very grateful to our University and more so to our department of Geomatic engineering and GIS for the opportunity they provided for us to perform this task.

\section{REFERENCES}

[1] Ouma, G. O., \& Ogallo, L. A. (2007). Desertification In Africa.

[2] Symeonakis E, Drake N. Monitoring desertification and land degradation over sub-Saharan Africa. International Journal of Remote Sensing. 2004 Feb 1; 25(3):573-92.

[3] Afifi AA, Gad A. Assessment and mapping areas affected by soil erosion and desertification in the north coastal part of Egypt. International Journal of Water Resources and Arid Environments. 2011; 1(2):83-91.

[4] Hill J, Stellmes M, Udelhoven T, Röder A, Sommer S. Mediterranean desertification and land degradation: mapping related land use change syndromes based on satellite observations. Global and Planetary Change. 2008 Dec 31; 64(3):146-57.

[5] Valor E, Caselles V. Mapping land surface emissivity from NDVI: Application to European, African, and South American areas. Remote sensing of Environment. 1996 Sep 1; 57(3):167-84.

[6] Thomas DS, Middleton NJ. Salinization: new perspectives on a major desertification issue. Journal of Arid Environments. 1993 Jan 1; 24(1):95-105.

[7] Hogg R. Development in Kenya: Drought, desertification and food scarcity. African Affairs. 1987 Jan 1; 86(342):47-58.

[8] Dregne HE, Chou NT. Global desertification dimensions and costs. Degradation and restoration of arid lands. 1992:73-92.

[9] Robinove CJ, Chavez PS, Gehring D, Holmgren R. Arid land monitoring using Landsat albedo difference images. Remote Sensing of Environment. 1981 Jan 1; 11:133-56.

[10] Wang XP, Li XR, Xiao HL, Pan YX. Evolutionary characteristics of the artificially revegetated shrub ecosystem in the Tengger Desert, northern China. Ecological Research. 2006 May 1; 21(3):415-24.

[11] Xu D, Kang X, Qiu D, Zhuang D, Pan J. Quantitative assessment of desertification using landsat data on a regional scale-a case study in the Ordos plateau, china. Sensors. 2009 Mar 12; 9(3):1738-53.

[12] Zheng M, Lai L, Jiang L, An P, Yu Y, Zheng Y, Shimizu H, Baskin JM, Baskin CC. Moderate water supply and partial sand burial increase relative growth rate of two Artemisia species in an inland sandy land. Journal of Arid Environments. 2012 Oct 31; 85:105-13.

[13] Boitt MK. Impacts of Mau Forest Catchment on the Great Rift Valley Lakes in Kenya. Journal of Geoscience and Environment Protection. 2016; 4(05):137.

[14] Geist HJ, Lambin EF. Dynamic causal patterns of desertification. Bioscience. 2004 Sep 1; 54(9):817-29. 